\title{
Intravesical Bacille Calmette-Guerin (BCG) Eradicates Bacteriuria in Antibiotic-Naïve Bladder Tumor Patients
}

\author{
Harry W Herr MD* \\ Memorial Sloan-Kettering Cancer Center, USA
}

*Corresponding author: Harry W Herr MD , Department of Urology, Memorial Sloan-Kettering Cancer Center, New York, USA.
Received Date: April 02, 2021

Published Date: April 28, 2021

\section{Introduction}

Intravesical Mycobacterium bovis bacille Calmette-Guerin (BCG) is standard therapy for high grade noninvasive bladder cancer. BCG induces a robust immune response in the bladder, characterized by cytokine production, inflammation, and recruitment of immune cells [1]. Neoplastic cells slough in the urine as they are destroyed, leaving denuded mucosa in responding patients. Invading uropathogens trigger similar cellular responses that cause rapid shedding of infected bladder epithelial cells into the urine, known as exfoliation [2]. Bacteria can evade exfoliation by invading deeper epithelial cells and establish a reservoir for urinary tract infection [3]. Although contraindicated in acute cystitis, we have shown that BCG is safe and effective in patients with asymptomatic bacteriuria [4]. We hypothesized that the immune response to BCG may augment innate immune defenses to eradicate bacteriuria.

Consecutive bladder tumor patients with asymptomatic bacteriuria were entered in a prospective pattern of care study approved by the institutional review board. Eighty-eight patients received induction BCG therapy and another 89 who had not received BCG underwent outpatient surveillance cystoscopy for low grade tumors. All patients had significant bacteriuria on voided urine culture ( $>104$ or $>105 \mathrm{cfu} / \mathrm{ml}$ with a single organism, usually E. coli or Enterococcus). None of the patients received pre-treatment antibiotics. Urine cultures were repeated at 3 and 6 months. End point was number of patients who were bacteria-free 6 months after their initial procedure. Bacteriuric patients undergoing cystoscopy were selected as controls because the procedure does not induce an immune response.

Febrile urinary tract infection occurred in 2 patients after BCG $(2.2 \%)$ and in 6 patients (6.1\%) after cystoscopy (P=.18). Infections resolved in 24 to 48 hours with antibiotics and no patient was admitted for sepsis. The Table 1 shows the characteristics and results in patients followed for 6 months who received no antibiotics. The groups were matched for age, sex, bacterial burden, and risk factors for urinary tract infection. Of 88 bacteriuric BCG-treated patients, $58(66 \%)$ became continuously infection-free compared to 16 of $89(18 \%)$ cystoscopy patients (P=.001). Majority of complete BCGresponders $(77 \%)$ converted to negative urine cultures. Infectionfree rates were similar in both groups of patients, whether they carried 104 or $105 \mathrm{cfu} / \mathrm{ml}$, suggesting an effect from BCG rather than transient bacteriuria.

Table1: Patient characteristics and results.

\begin{tabular}{|c|c|c|}
\hline \multicolumn{3}{|c|}{ Patient characteristics and results } \\
\hline Variable & BCG Therapy & Cystoscopy \\
\hline No. patients & 88 & 89 \\
\hline
\end{tabular}




\begin{tabular}{|c|c|c|}
\hline Age in years: median (range) & $70(37-93)$ & $71(38-98)$ \\
\hline Sex: males & $57(65 \%)$ & $60(64 \%)$ \\
\hline \multicolumn{3}{|c|}{ Bacterial load } \\
\hline$>104 \mathrm{cfu} / \mathrm{ml}$ & $36(41 \%)$ & $43(48 \%)$ \\
\hline$>105 \mathrm{cfu} / \mathrm{ml}$ & $52(59 \%)$ & $46(52 \%)$ \\
\hline \multicolumn{3}{|c|}{ Risk factor for urine infection } \\
\hline prior/current smoker & $65(74 \%)$ & $63(71 \%)$ \\
\hline diabetes & $7(8 \%)$ & $5(6 \%)$ \\
\hline $\mathrm{BPH}$ & $23(26 \%)$ & $19(21 \%)$ \\
\hline$>65$ years & $62(70 \%)$ & $58(65 \%)$ \\
\hline steroids & 3 & 2 \\
\hline \multicolumn{3}{|c|}{ Follow-up urine cultures } \\
\hline no growth & $58(66 \%)^{*}$ & $16(18 \%)^{*}$ \\
\hline$>104$ or $>105 \mathrm{cfu} / \mathrm{ml}$ & $30(34 \%)$ & $73(82 \%)$ \\
\hline
\end{tabular}

Hazard ratio=3.6 $(95 \% \mathrm{Cl}, 2.1-6.4) ; \mathrm{P}=.001$

Intravesical BCG therapy appears to eradicate urinary tract uropathogens and malignant cells in antibiotic-naïve bladder cancer patients, possibly due to augmented active and innate host immunity. Study design, however, does not allow causal inference of an effect of BCG on bacteriuria.

\section{Acknowledgement}

\section{None}

\section{Conflict of interest}

None

\section{References}

1. Bohle A, Brandau S (2003) Immune mechanisms in BCG immunotherapy for superficial bladder cancer. J Urol 170(3): 964-969.

2. Mysorekar IU, Hultgren SJ (2006) Mechanisms of uropathogenic Escherichia coli persistence and eradication from the urinary tract. Proc Natl Acad Sci U S A 103(38): 14170-14175.

3. Muenzner P, Bachmann V, Zimmermann W, Jochen Hentschel, Christof R Hauck (2010) Human-restricted bacterial pathogens block shedding of epithelial cells by stimulating integrin activation. Science 329(5996): 1197-1201.

4. Herr HW (2011) Intravesical bacille Calmette-Guerin in patients with asymptomatic bacteriuria. JAMA 305(14): 1413-1414. 